У,

ББК 67.405.1

DOI 10.22394/1682-2358-2021-5-50-58

A.A. Ivanov, Candidate of Sciences (Law), Docent of the Labor Law Department, Saratov State Academy of Law

Yu.A. Kondrashov, Candidate of Sciences (Law), Docent of the Theory of State and Law Department, Saratov State Academy of Law

\section{PARTICIPATION OF PEDAGOGICAL WORKERS IN THE STATE FINAL CERTIFICATION: LEGAL ISSUES}

Issues of using teachers' labor during the period of state final certification in the formats of the Unified State Exam / Main State Exam are considered. The questions of legality of teachers' involvement in the organization of state final certification are analyzed. The conclusion about the necessity to apply the contractual form to the specified relations is made

Key words and word-combinations: state final certification, Unified State Exam, Labor Code of the Russian Federation, teaching staff, overtime work.
А.А. ИВанов, кандидат юридических наук, доцент кафедрьг трудового права Саратовской государственной юоридиеской академии (email: artiom-depeche@yandex.ru)

Ю.А. Кондрашов, кандидат юоридиеских наук, доиент кафедри теории государства и права Саратовской государственной норидической академии (email: yakondor@mail.ru)

\section{УЧАСТИЕ ПЕААГОГИЧЕСКИХ РАБОТНИКОВ В ПРОВЕАЕНИИ ГОСУААРСТВЕННОЙ ИТОГОВОЙ АТТЕСТАЦИИ: ПРАВОВЫЕ ВОПРОСЫ}

Аннотация. Рассматриваются вопросы применения труда педагогических работников в период проведения государственной итоговой аттестации в форматах ЕГЭ / ОГЭ. Подвергается анализу законность привлечения педагогических работников к участию в организации государственной итоговой аттестации. Делается вывод о необходимости применения договорной формы к указанным отношениям.

Ключевые слова и словосочетания: государственная итоговая аттестация, ЕГЭ, Трудовой кодекс Российской Федерации, педагогические работники, сверхурочная работа.

$\mathrm{V}$ читель городской и особенно сельской школы - профессия крайне благородная. Нередко педагоги вопреки 
АОвольно скромной оплате труАа, а иногАа вслеАствие несправедливого отношения администрации, а также в результате процессов маргинамизации общества самоотверженно и добросовестно выполняют свою соџиальную миссию. К сожкалению, выпускники педагогических вузов сегодня не только не торопятся с трудоустройством по специальности, но дажке в принципе не рассматривают работу в школе, выбирая совершенно Аругую сферу Аеятельности [1]. Причин такого негативного явления много. Кроме невысокой заработной платы, это непростая целевая аудитория - учащиеся и их родители. Речь идет не о банальной невоспитанности и непорядочности, а об учащихся и их родитемях, которые ведут маргинальный образ жизни, сопровождающийся систематическим девиантным, граничащим с уголовным поведением. В результате не имеющие социального опыта и еще ментально слабые молодые специалисты уходят в частное репетиторство или вовсе покиАают профессию.

В современных российских школах наблюдается негативная тенденция старения каАров, существует дефицит учителей среднего возраста на фоне выбытия учителей старшего поколения. Учителя констатируют, что молодежь после окончания соответствующих вузов в школы не торопится иАти работать; из профессии ухоАят АюАи среАнего возраста на самом пике своей работоспособности; пеАагоги-пенсионеры вынуждены оставаться, так как не надеются вновь трудоустроиться, особенно если это учитель, например, изобразительного искусства [2, с. 66].

Еще одна сложность связана с выполнением обязанностей, прямо не предусмотренных ни трудовым Аоговором, ни Аолжностными инструкциями, вызываюших правовые вопросы, к выполнению которых из года в гоА ПонужАают учитемей неАобросовестные администраџии школ, - участие в организации государственной итоговой аттестации в форматах ЕГЭ / ОГЭ.

В начале нумевых годов введение ЕГЭ стало направлением, следование по которому означало модернизацию существующей на тот момент системы образования. Очевидно, внеАрение нового формата государственной итоговой аттестации (ГИА) было актуально с точки зрения необходимости соответствия существующим на межАународном уровне ценностям и стандартам. Введение ЕГЭ предполагамо выполнение конкретных задач [3], прежде всего формирование максимально объективной системы оџенки и подготовки будущих абитуриентов. САача ЕГЭ и его результаты направлены на Аальнейшее поступцение в вуз, соответственно, смежной его задачей явцяется формирование объективной картины вступитемьных испытаний и 
Аальнейшего приема в высшие учебные заведения. Внедрение ЕГЭ инструмент, который априори направлен на миквидацию коррупџионного элемента при поступцении в вуз, так как подразумевается, что набравшие максимальное количество бамлов выпускники будут объективно претендовать на бюджетные места. Своего рода сверхзадачей, стоящей переА ЕГЭ, становится создание единой системы, направленной на признание полученных на экзамене бамлов во всех вузах страны.

С начала введения ЕГЭ и до настоящего времени у этой формы контроля есть свои и противники, и сторонники по вполне объективным причинам. Рассмотрим некоторые из них. Так, сам проџесс проведения государственной итоговой аттестации имеет определенные неудобства. Аети саают экзамен, как правицо, на территории своего района, но в стенах чужкй школы, что обостряет нервное напряжкение и создает и без того не самое кучшее психо-эмоциональное состояние выпускников, как и запрет на участие в нем учителей из своей школы, - в пункте проведения экзамена задействованы учителя из школ со всего района. Очевидным недостатком ЕГЭ является проверка тестовой части контрольно-измерительных материалов (КИМ) компьютером. Проверка второй части ЕГЭ (развернутые ответы по обществознанию; составление плана по теме, содержащейся в КИМ; написание эссе по предложенным высказываниям) проводится заранее отобранными экспертами (учителями-предметниками), которые могут расходиться в своих оценках, что впоследствии нереАко заканчивается апемяџией.

Еще одним немаловажным недостатком практики проведения государственной итоговой аттестации в формате ЕГЭ / ОГЭ явцяется тот факт, что школьники с пятого по десятый класс изучают материац по предмету, который сдают в конце одиннадџатого класса и, открыв кодификатор, понимают:

1) школьных знаний, полученных при изучении выбранного Аця сАачи ЕГЭ, явно недостаточно;

2) содержание кодификатора - тематическая база - выходит дацеко за рамки не только полученных в школе знаний, но и вкцючает материал, не изучаемый в период обучения.

Обозначенные Ава пункта не только показатели трудностей организации подготовки к ЕГЭ / ОГЭ, но связаны с Аавно назревшими проблемами школьного образования в целом. Недопустимой, к примеру, явмяется ситуация, когда в кодификаторе по обществознанию содержатся темы и вопросы, которые изучаются на последних курcax профилирующих вузов. Это означает, что среАнестатистический 
школьник для прохождения порога, связанного с набором минимального количества балмов, при поступлении в выбранный вуз Аолжен изучить предмет всеми доступными среАствами, включая репетиторов, и разобраться в материале академического уровня. Можно понять нежелание учителей-предметников на добровольных началах без оплаты сверхурочной работы заниматься подготовкой к ЕГЭ / ОГЭ; если же в школе предусмотрены эмективные занятия по подготовке к государственной итоговой аттестации, то не всегда на них достаточно выдеменного времени.

Очевидным недостатком ЕГЭ / ОГЭ явцяется проблема, которая цежит в плоскости организации системы народного школьного образования, - перекладывание ответственности в случае низких результатов на учителей-преАметников. При этом ни в трудовом, ни в образовательном законодательстве нет нормы, предусматривающей Аисциплинарную ответственность педагогического работника за то, что его ученики набрами низкие бамлы на ЕГЭ / ОГЭ. Низкие бамлы являются результатом не столько бездействия учителей по подготовке к ГИА (такая подготовка Аолжна осуществляться в школе организованно, с соответствующей опцатой труда пеАагогов), сколько отсутствием мотивации и безответственным отношением непосреАственной целевой аудитории. ОАнако учителю в такой ситуации приходится, как правило, слушать упреки в свой аАрес, которых он не заслуживает. Известны даже случаи попыток привлечения учителей к Аисџиплинарной ответственности за низкие баммы на ЕГЭ / ОГЭ [4] . Общей проблемой становится нервное истощение учащихся и учитемей в проџессе проведения ГИА. В 2019 г. бым случай, когда выпускница скончалась на ЕГЭ [5].

Среди факторов, оказывающих негативное влияние на здоровье педагогических работников, специалисты называют, кроме использования информационных технологий, систему постоянного совершенствования системы ЕГЭ [6, с. 105], когАа происходит увеличение не только физической, но и психо-эмоциональной нагрузки на педагогов, участвующих в ГИА. При этом ужесточаются административные санкции, связанные с проведением ГИА, в результате чего растет постоянная тревога среди педагогов быть подвергнутыми административной ответственности.

Возникает вопрос, насколько правомерно привлечение педагогических работников к участию в проџедуре проведения ГИА в форматах ЕГЭ / ОГЭ. В трудовых АОговорах с учителями такой непосреАственной обязанности нет, и деятельность эту они осуществцяют не на террито- 
рии своих работодателей, что целесообразно проанализировать с позиции норм трудового и образовательного законодательства.

В нормах Трудового кодекса РФ данная деятельность прописана как сверхурочная работа [7]. ОАнако ограничиваться в Аанном вопросе только правилами ст. 99 ТК РФ некорректно.

Некоторые специалисты исходят из того, что участие педагогов в ЕГЭ / ОГЭ явцяется производственной необходимостью, и, следовательно, этот вопрос Аолжен быть решен по соглашению сторон. Как отмечают исследователи, у руководителей есть преимушественное право на привлечение к участию в ЕГЭ / ОГЭ [8, с. 128]. ОАнако в соответствии со ст. 72.2 ТК РФ также преАусмотрено, что перевод работника без его согласия на срок до одного месяџа на необусловленную трудовым договором работу у того же работодателя допускается в случаях простоя, необходимости предотвраще-

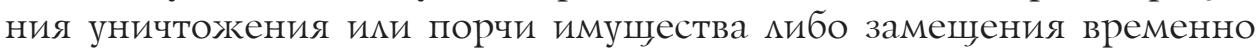
отсутствующего работника, вызванного чрезвычайными обстоятельствами. Очевидно, что проџедура проведения ГИА не явмяется той необходимостью, о которой в Аанной статье идет речь. В Аанной статье также закреплено, что перевод на Аругую работу с более низкой квалификацией допускается только с письменного согласия работника. По смыслу последней нормы, работа в качестве организатора ЕГЭ / ОГЭ не требует особых спеџиальных знаний и навыков, и, значит, Аля нее необходимо письменное согласие педагогического работника. ОАнако в педагогической практике чаще всего используются понуждения администрации школ к написанию учитемями согласия на подобную работу [9]. Отметим, что в указанной статье не названо участие в ГИА.

В нормах ТК РФ, посвященных правовому регулированию государственных и общественных обязанностей, также не упоминается участие в ЕГЭ / ОГЭ. ОАнако специалисты, приводя перечень государственных и общественных обязанностей работников, называют среди них выполнение Аругих государственных или обшественных обязанностей в случаях, предусмотренных законом [10, с. 2].

В соответствии с Федерацьным законом от 29 декабря 2012 г. № 273-Ф3 «Об образовании в Российской Федерации» педагогические работники привлекаются к участию в проведении ЕГЭ по решению уполномоченных органов исполнительной власти [11]. Такая формуцировка вызывает множество вопросов, но главный из них, насколько законно привлекать тех или иных пеАагогических работников к выполнению данных обязанностей и могут ми они отказаться от этого? В соответствии с Порядком № 1394 органы исполнительной вмасти

54 Bulletin of the Volga Region Institute of Administration • 2021. Vol. 21. № 5 
субъектов РФ, ведающие вопросами управления образованием, домжны обеспечить подготовку и отбор специалистов, а также руководителей и организаторов Амя проведения ЕГЭ [12]. Тем не менее актуацьным остается вопрос, может ми педагогический работник избежкать участия в отборе? В соответствии с п. 1.1 приказа Минобрнауки РФ от 11 мая 2016 г. № 536 «Об утверждении особенностей режкима рабочего времени и времени отдыха педагогических и иных работников организаций, осуществляющих образовательную деятельность», устанавливаются правила регулирования режкима рабочего времени и времени отдыха педагогических работников, занимающих должности, перечисленные в номенклатуре Аолжностей пеАагогических работников организаций, осуществляющих образовательную Аеятельность, Аолжностей руковоАителей образовательных организаций, утвержденной постановлением Правительства РФ от 8 августа 2013 г. № 678 [13; 14]. В соответствии с номенклатурой к педагогическим работникам относятся должности педагога Аополнительного образования; педагога-библиотекаря; педагога-организатора; педагога-психолога; преподавателя; преподавателя-организатора основ безопасности жизнедеятельности; старшего педагога дополнительного образования; старшего тренера-преподавателя; тренера-преподавателя; тьютора; учителя; учителя-дефектолога; учителя-логопеда.

По общему правицу, в соответствии с ч. 6 ст. 47 Федерального закона «Об образовании в Российской Федерации» конкретные Аолжностные обязанности рассматриваемой категории работников определяются трудовым Аоговором и АОлжностными инструкциями. В свою очередь, Аля разработки Аолжностных инструкщий, которые содержкат обязанности педагогических работников, применяются Квацификационные характеристики домжностей работников образования, утвержденные приказом Минздравсоџразвития России от 26 августа 2010 г. № 761н [15], среди которых нет обязанности педагогических работников, связанной с подготовкой и проведением ЕГЭ / ОГЭ. Исходя из письма Минобрнауки России от 15 октября 2015 г. № 08-ПГ-МОН-37849, работодатемь не может понудить пеАагога выполнять не предусмотренные квалификационной характеристикой по занимаемой им Аолжности обязанности без его письменного согласия [16].

Таким образом, педагогические работники могут быть привлечены к процеАуре проведения ЕГЭ только с письменного согласия и Аополнительной оплатой труда.

За работу в проведении ГИА в форматах ЕГЭ / ОГЭ по общему правику, в соответствии с Федеральным законом «Об образовании в 
Российской Федерации», педагогическим работникам, участвующим по решению уполномоченных органов исполнительной власти в проведении единого государственного экзамена в рабочее время и освобожденным от основной работы на период проведения ЕГЭ, предоставцяются гарантии и компенсации, установленные трудовым законодательством и иными актами, содержащими нормы трудового права. Размер и порядок выплаты указанной компенсации устанавливаются субъектом РФ за счет бюджетных ассигнований региона, выделяемых на проведение ЕГЭ / ОГЭ.

В письме Минобрнауки РФ от 26 мая 2016 г. № 02-226 содержится рекомендация органам, осуществляющим управление в сфере образования, разработать нормативный правовой акт на уровне субъекта РФ по вопросам выплаты компенсации за участие в проведении ЕГЭ [17].

В соответствии с п. 2.3 приказа Минобрнауки России от 11 мая 2016 г. № 536 компенсация за участие в ЕГЭ не приравнена к Аополнительным видам работ, выполняемых по трудовому договору. В письме № 02-226 компенсация за участие в проведении ЕГЭ значится как Аополнительная оплата труда.

В соответствии с Федеральным законом «Об образовании в Российской Федерации» и приказом № 536 предусмотрена отдельная компенсация педагогическим работникам за участие в проведении ЕГЭ, так как указанная работа в пункте проведения экзамена не преАусмотрена их должностными обязанностями, которые прописаны в квацификаџионных характеристиках. Очевидно, что для начисления и выплаты компенсации необходимо осуществцять по соответствующему Положению субъекта РФ о выплате после письменного Аоговора с работником.

На основании изложенного можно сделать следующие выводы.

По общему правилу, содержкащемуся в п. 9 ст. 47 Федерального закона «Об образовании в Российской Федерации», за участие в организации и проведении ГИА предусмотрена компенсация педагогическим работникам, размеры, сроки и процедура выплаты домжны быть прописаны на уровне субъекта РФ.

Негативная практика привлечения в приказном порядке к выполнению обязанностей, связанных с проведением ГИА в форматах ЕГЭ / ОГЭ, распространилась из-за некорректной и расплывчатой формуиировки нормы, содержащейся в п. 9 ст. 47 Федерального закона «Об образовании в Российской Федераџии», Аопускающей вольное толкование, что ведет к путаниџе на практике. По мнению преАставителей органов исполнительной власти, занимающихся вопросами

56 Bulletin of the Volga Region Institute of Administration • 2021. Vol. 21. № 5 
народного образования, участие в организации ЕГЭ / ОГЭ явцяется исполнением государственных и общественных обязанностей и, слеАовательно, к данным отношениям, возникающим межАу учителями и органами исполнительной власти в сфере образования, не применима договорная форма, равно как и отказ педагогических работников от Аанной работы. Расплывчатость формулировки указанного положения ведет к тому, что в каждом регионе своя сложившаяся практика привлечения и размеры компенсации. Аля преодоления подобной ситуации данные отношения следует оформиять искАючительно в договорной форме на принципе добровольности, а соответствующую норму закрепить в Федеральном законе «Об образовании в Российской Федерации».

Участие педагогических работников в проведении ГИА - дело сугубо добровольное. Ни в оАних Аолжностных инструкциях и нормативных правовых актах в сфере народного образования не прописано должностных обязанностей по участию в ГИА. Это, оАнако, означает, что работодатель (Аиректор школы, который подает список педагогов на участие в организации ЕГЭ / ОГЭ) не можкет в одностороннем порядке, без соглашения сторон, менять Аолжностную инструкцию. В случае если школьная администрация по своей инициативе неправомерно внесла изменения в должностные обязанности, то следует через профсоюзную организацию добиваться отмены вкцюченной обязанности по участию в ГИА, тем более что отношения по поводу участия в ЕГЭ / ОГЭ возникают не межАу Аиректором школы и педагогами, а учителями разных школ и органами исполнительной вцасти в сфере образования. Именно поэтому, если аАминистрация школы внесла учителя в список организаторов ЕГЭ / ОГЭ, то педагогический работник имеет полное право письменным заявлением на имя директора школы отозвать себя из данного списка.

\section{Библиографический список}

1. Воробьева И.В. Престиж профессии учителя // Вестник РГГУ. Сер.: Философия. Социология. Искусствоведение. 2014. № 4 (126). С. 247-254.

2. Авраамова Е.М., Логинов Д.М. Какие кадры работают в школах России? // Народное образование. 2017. № 3-4. С. 65-79.

3. Черных A.M. Единый государственный экзамен как современный измерительный инструмент, новая форма аттестации и механизм преемственности общего и профессионального образования // Сибирский педагогический журнал. 2008. Вып. 11. С. 434-445.

4. Наказания учителей за низкие результаты ЕГЭ незаконны. URL: https://ctege. info/stati-o-ege/nakazaniya-uchiteley-za-nizkie-rezultatyi-ege-nezakonnyi.html 
5. Выпускница умерла во время ЕГЭ по математике. URL: https://versia.ru/genprokuratura-rf-obzhaluet-prisuzhdenie-yeks-strukture-yukosa-26-mlrd

6. Печеркина А.А., Муслумов Р.P. Сохранение и укрепление профессионального здоровья учителя // Народное образование. 2017. № 1-2. С. 105-110.

7. Трудовой кодекс Российской Федерации от 30 дек. 2001 г. № 197-Ф3 (с изм. от 2 июля 2021 г. № 311-ФЗ) // СЗ РФ. 2002. № 1 (ч. І). Ст. 3.

8. Юридические консультации // Народное образование. 2010. № 1. С. 128.

9. Учителя о том, как из них сделали рабов. URL: https://novayagazeta.ru/articles/2020/06/26/86028-my-slishkom-ustali-dlya-bunta

10. Алексеева Г.И. Гарантии и компенсации работникам при исполнении государственных и общественных обязанностей // Бухгалтерский учет в бюджетных и некоммерческих организациях. 2017. № 4. С. 2-15.

11. Об образовании в Российской Федерации: Федер. закон от 29 дек. 2012 г. № 273-Ф3 (с изм. от 2 июля 2021 г. № 351-Ф3) // СЗ РФ. 2012. № 53 (ч. 1). Ст. 7598.

12. Об утверждении Порядка проведения государственной итоговой аттестации по образовательным программам основного общего образования: приказ Минобрнауки России от 25 дек. 2013 г. № 1394 (в ред. от 9 янв. 2017 г.) [Электронный ресурс]. Доступ из СПС «КонсультантПлюс».

13. Об утверждении особенностей режима рабочего времени и времени отдыха педагогических и иных работников организаций, осуществляющих образовательную деятельность: приказ Минобрнауки от 11 мая 2016 г. № 536 // Бюллетень нормативных актов федеральных органов исполнительной власти. 2016. № 28.

14. Об утверждении номенклатуры должностей педагогических работников организаций, осуществляющих образовательную деятельность, должностей руководителей образовательных организаций: постановление Правительства РФ от 8 авг. 2013 г. № 678 // С3 РФ. 2013. № 33. Ст. 4381.

15. Об утверждении Единого квалификационного справочника должностей руководителей, специалистов и служащих, раздел «Квалификационные характеристики должностей работников образования»: приказ Минздравсоцразвития России от 26 авг. 2010 г. № 761н // Российская газета. 2010. 20 окт.

16. О продолжительности рабочего времени и особенностях, связанных с режимом рабочего времени педагогических и других работников образовательных организаций: письмо Минобрнауки России от 15 окт. 2015 г. № 08-ПГ-МОН-37849 [Электронный ресурс]. Доступ из СПС «КонсультантПлюс».

17. О выплате компенсации педагогическим работникам, участвующим в проведении государственной итоговой аттестации: письмо Минобрнауки от 26 мая 2016 г. № 02-226 [Электронный ресурс]. Доступ из СПС «КонсультантПлюс». 